\title{
Morphology of Pits and Fissures Reviewed through Scanning Electron Microscope
}

\author{
Richa Khanna $^{1 *}$, Ramesh K Pandey² and Neerja Singh ${ }^{2}$
}

${ }^{1}$ Department of Pedodontics, King George's Medical University, Lucknow, Uttar Pradesh, India

${ }^{2}$ Department of Pedodontics and Preventive Dentistry, King George's Medical University, Lucknow, Uttar Pradesh, India

\begin{abstract}
Pit and fissures in permanent human teeth have been an area of constant research for long, as the advancements in preventive regimens in dentistry paves in ways to prevent dental caries. The complexity of these areas inmorphological terms has been studied and explained. The present study is a review of their morphology examined under Scanning Electron Microscope. The study also examines the penetration of sealants in fissures of different morphology.
\end{abstract}

Keywords: Pit and fissures; Scanning electron microscope

\section{Introduction}

Our dental profession is becoming increasingly interested in the available preventive regimens as the benefits of these regimens become scientifically and clinically demonstrated all over the world. The pit and fissure system, on occlusal surfaces of human posterior teeth represent vulnerable sites for initiation of dental caries due to their morphological complexity. Sealing of these complex sites has been a major development in preventing pit and fissure caries, first initiated by Hyatt [1]. The pit and fissure systems and the sealing materials have long been a subject of dental research. Robertson [2] in 1841 was one of the first research workers suggesting possibilities of small openings on occlusal surfaces of posterior teeth leading to large cavities. $\mathrm{He}$ also illustrated a fissure extending into dentin in his book 'A Practical treatise on the human teeth'.

The deep invaginations of these systems have been illustrated by many of the research workers so far. Gillings and Buonocore [3] in their study found that these invaginations may sometime even extend upto the dentinoenamel junction, but with dentin not exposed. Taking into account the complexity of pit and fissure systems, for the sake of simplicity they were broadly classified as

(1) Shallow and wide 'V' or ' $U$ ' shaped fissures.

(2) Deep and narrow 'I' or ' $K$ ' shaped fissures.

The V/U shaped fissures are self-cleansing and somewhat caries resistant. The I/K shaped fissures are caries susceptible and may have branches to increase complexity. The percentage of these occlusal fissure types were found by Cho and Kim in 1989 [4] as 58.0\%-I, $21.0 \%-\mathrm{U}, 15.0 \%-\mathrm{K}, 6.0 \%-\mathrm{V}$, average depth of occlusal fissure were found to be $1.15 \mathrm{~mm}$ in I type, $0.53 \mathrm{~mm}$ in U type, $1.11 \mathrm{~mm}$ in $\mathrm{K}$ type, $0.56 \mathrm{~mm}$ in $\mathrm{V}$ type.

The following study under scanning electron microscope was carried out to review the complex anatomy of the pit and fissure systems of human permanent molars.

\section{Materials and Method}

Human permanent posterior teeth with intact occlusal surfaces, extracted due to patients' will, root caries or periodontal reasons were collected and stored in $10 \%$ formalin solution for 24 hours. The teeth were embedded in self cure acrylic resin (DPI-RR) blocks and were cleaned with pumice slurry with a bristle brush in a slow speed handpiece. The teeth were rinsed. The teeth were divided into two groups: (a) For examination of occlusal aspect of the fissure-10 teeth

(b) For examination of vertical aspect (depth) of the fissure-20 teeth.

In group (a) the coronal part of the tooth, about $2 \mathrm{~mm}$ in height was cut from the remaining tooth structure with the help of a water cooled blade (Microdont). After sectioning, the specimens were immediately preoared for SEM examination as follows - The obtained specimens were cleaned in an ultrasonic vibrator (Bransonic 221) for 5 minutes. All specimens were then kept in $90 \%$ alcohol in a glass beaker and then placed in ultrasonic vibrator (Bransonic 221) for 5 minutes. The specimens were then dried under white light, and fixed onto aluminium stubs with the help of adhesive films. A drop of electroconductive silver paint (Dotite-EMS) was placed on two diametric opposite positions of the specimen fixed on the stub, caring not to cover the area to be examined. The specimens were then coated with a conductive layer of gold-palladium alloy with the help of a sputtering device (Poloran). They were then examined under the scanning electron microscope LEO 430. The observations were recorded on polaroid films.

In group (b) the sample teeth were again divided into two sub groups with 10 teeth each: subgroup (1): no sealant application, subgroup (2): fissure system with sealant application. For sealant application the fissures were treated with $37 \%$ phosphoric acid gel (Dentsply) for 30 seconds with the help of a disposable brush, rinsed with distilled water for 10 seconds, and then dried with oil free compressed air. The etched surfaces of enamel at the entrance of each fissure system were examined to assure the frosted appearance. The sealant (Clinpro, 3M) was then applied to the etched fissure systems following manufacturer's instructions. To prevent voids and air entrapment, the sealant was gently teased through the fissure with the $0.5 \mathrm{~mm}$ tip of a periodontal probe (API) and was then polymerized using a light-cure unit (Optilight LD III, Gnatus) for 40 seconds. The teeth in both subgroups were slit longitudinally through the fissures with a water cooled diamond blade creating sections of 1 to $1.5 \mathrm{~mm}$ thickness and dimensions no more

*Corresponding author: Richa Khanna, Department of Pedodontics, King George's Medical University, Lucknow, Uttar Pradesh, India, Tel: 9936038511 E-mail: richa.bahal@gmail.com

Received April 01, 2014; Accepted March 05, 2015; Published March 08, 2015

Citation: Khanna R, Pandey RK, Singh N (2015) Morphology of Pits and Fissures Reviewed through Scanning Electron Microscope. Dentistry 5: 287. doi:10.4172/2161-1122.1000287

Copyright: $\odot 2015$ Khanna R, et al. This is an open-access article distributed under the terms of the Creative Commons Attribution License, which permits unrestricted use, distribution, and reproduction in any medium, provided the original author and source are credited. 
Citation: Khanna R, Pandey RK, Singh N (2015) Morphology of Pits and Fissures Reviewed through Scanning Electron Microscope. Dentistry 5: 287. doi:10.4172/2161-1122.1000287

than $2 \mathrm{~mm}$ by $2 \mathrm{~mm}$ (length by width). The specimens were cleaned and prepared as in group (a) for examination under scanning electron microscope and observations were recorded on Polaroid films.

\section{Observations}

Examination of group (a) specimens under scanning electron microscope reveals the complex anatomy of the fissure system from the occlusal aspect with its numerous ramifications (Figures 1a and 1b). The entire system was seen as an assembly of more than ten, or even more pits confluent with each other by the connecting primary, secondary and supplemental fissures. In addition several surface porosities not noticed clinically were clearly visible.

Examination of group (b) revealed longitudinal depth of the fissure systems both with and without sealant placement. It was found that fissures were not empty spaces, but, rather were filled with some debris (Figures 2 and 3). The fissures as seen under scanning electron microscope reached close to the dentinoenamel junction (Figure 4). The average distance of the base of the fissure from the DEJ in the studied samples was found to be $0.54 \mathrm{~mm}$ as measured on a

a)

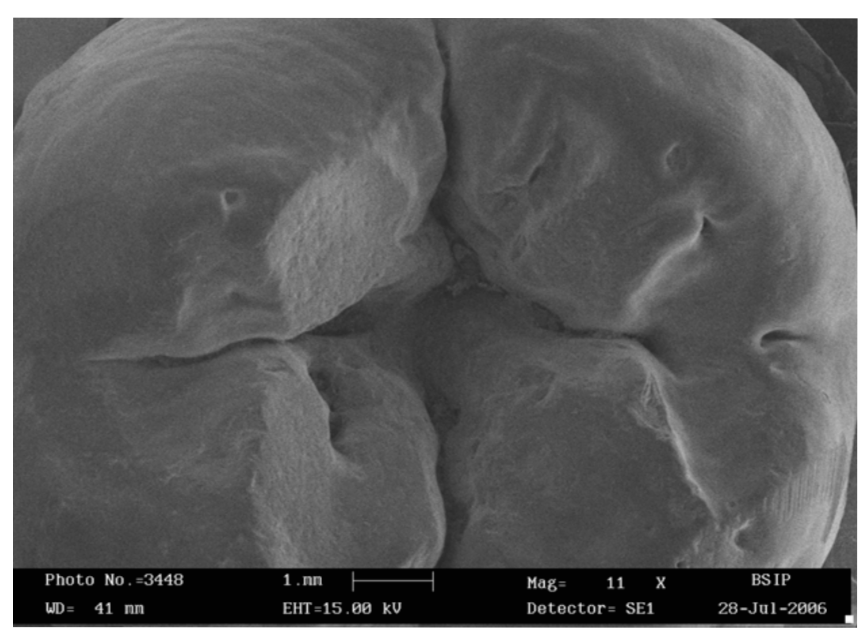

b)

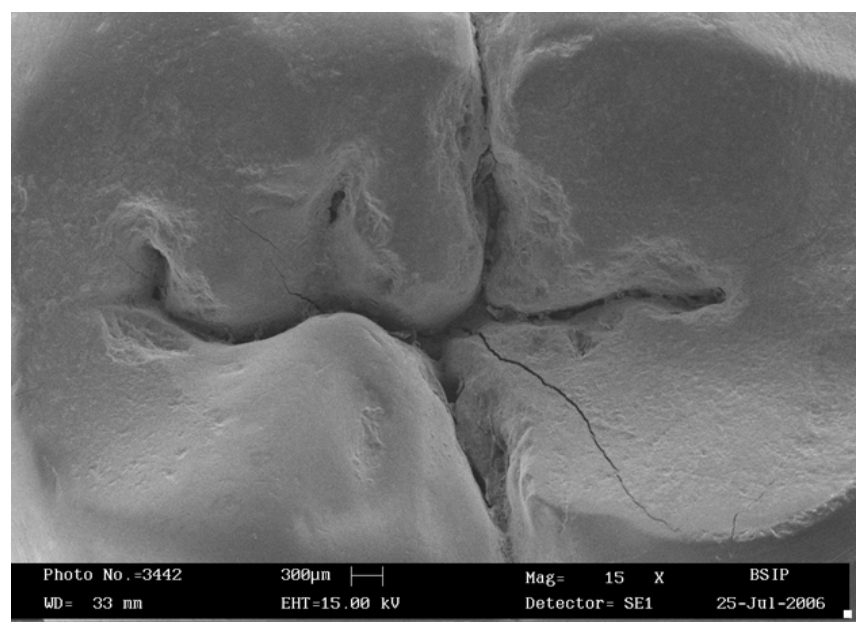

Figure 1a and 1b: Examination of group (a) specimens revealing the complex anatomy of the fissure system from the occlusal aspect with its numerous ramifications.

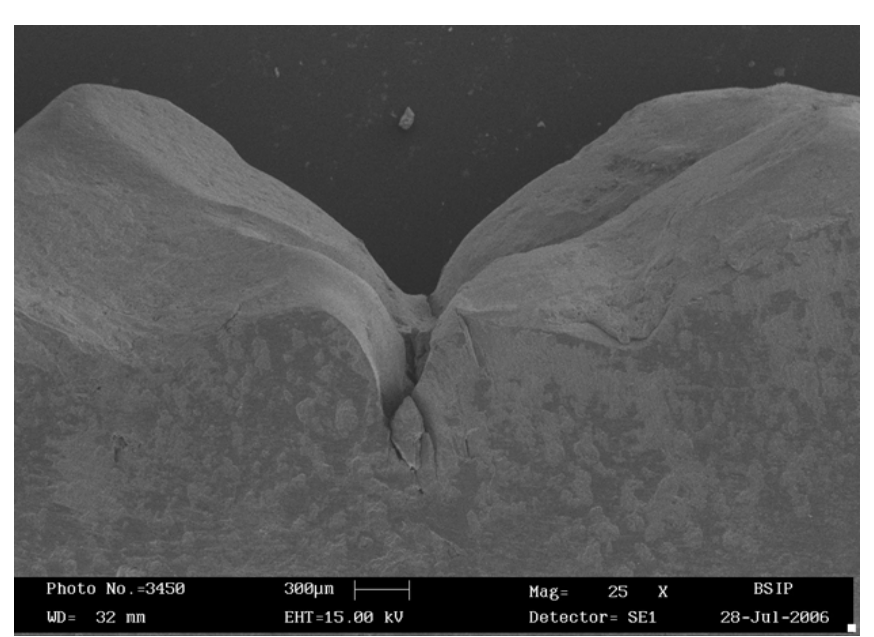

Figure 2: Examination of group (b) specimen showing longitudinal depth of the fissure systems without sealant placement.

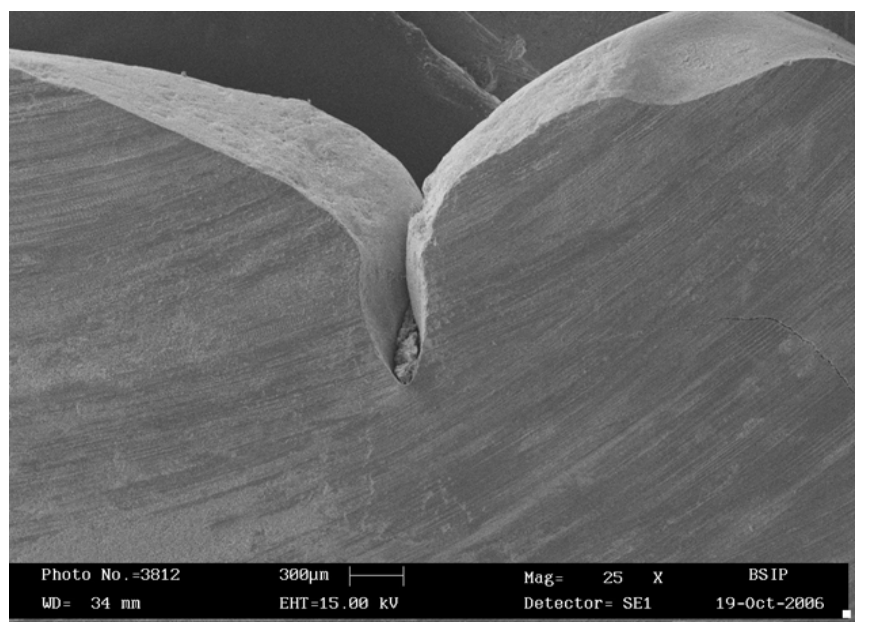

Figure 3: Examination of group (b) specimen showing longitudinal depth of the fissure systems both with sealant placement.

Gateway 2000 computer using the free UTHSCSA Image Tool program (developed at Department of Dental Diagnostic Science, University of Texas Health Science Centre, San Antonio, Texas) and available from Internet [5]. In fissures with sealant placement, the sealant was unable toflow to the base of the fissure in narrow fissures (Figure 5). The wide fissures did allow better penetration of the sealant, but the extreme base was still not reachable (Figure 6).

\section{Discussion}

The morphological complexity and the related vulnerability to dental caries have been cited by many authors in literature. The results of a study by Marianne Juhl [6] confirm that the morphology on occlusal surfaces of molars is extremely variable with numerous pits of considerable length positioned at various angles relative to the fissures as found in our study. According to Ripa et al. [7] this accounts for plaque accumulation to the extent that the enamel in pit and fissures is not able to receive the same level of caries protection from fluoride as does smooth surface enamel. The findings of this study confirm to this complexity. 
Citation: Khanna R, Pandey RK, Singh N (2015) Morphology of Pits and Fissures Reviewed through Scanning Electron Microscope. Dentistry 5: 287. doi:10.4172/2161-1122.1000287

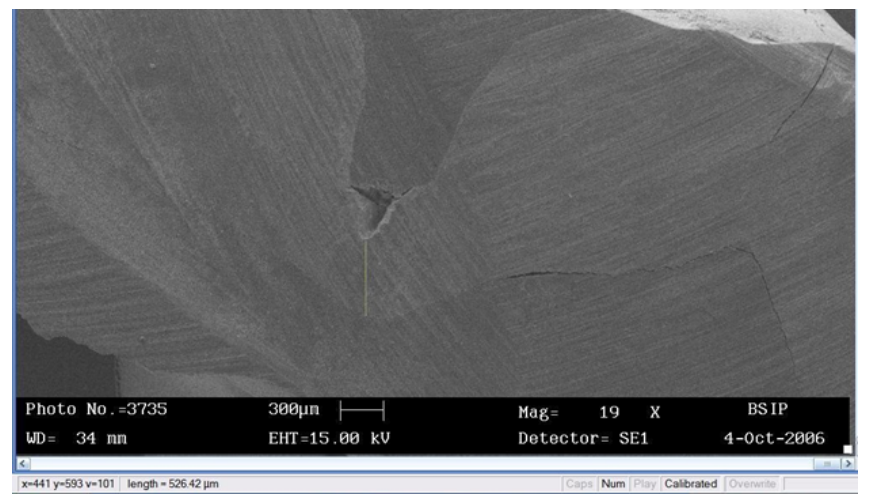

Figure 4: Fissures seen under scanning electron microscope reached close to the dentinoenamel junction.



Figure 5: In fissures with sealant placement, the sealant was unable to flow to the base of the fissure in narrow fissures.

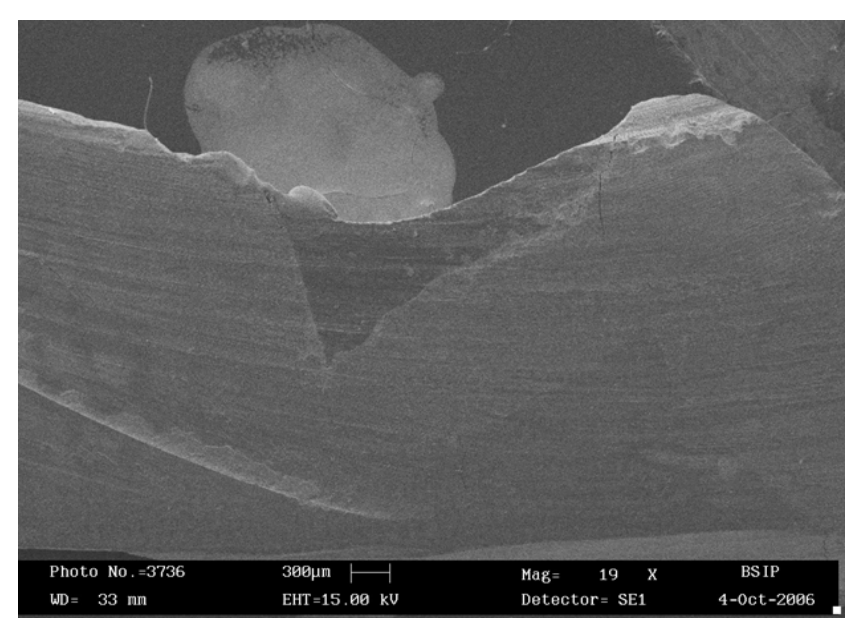

Figure 6: The wide fissures did allow better penetration of the sealant, but the extreme base was still not reachable.

The longitudinal depth of the fissures as seen under SEM revealed variable morphology in the present study. The closeness of these fissures to the DEJ was assessed. Even at such higher magnification there was doubt that these areas could be self-cleansing. The constriction at base of most of the fissures seen in the pictures gives rise to the possibility of bacterial accumulation. Galil and Gwinnett [8] in 1975 studied the contents of fissures to examine their post-eruptive microbial colonization. While the upper portions of fissures contained a large number of distinct cocci and bacilli, the bottom of the fissures contained an amorphous mass of material with few recognizable bacteria and strong evidence of mineralization.

It was also found in this study that some space was left in most of the base of the fissures after sealant placement.

Powell et al. [9] concluded from his study that 334 out of 390 wide fissures examined were completely filled by the sealant material. In contrast, only 28 of the 650 constricted fissures examined were completely filled by these resins. Sutalo et al. [10] described the morphological types of fissures system in permanent human molars, their average depth and width as well as the penetration capacity of fissure in relation to the morphological type of the fissure established $(\mathrm{V}, \mathrm{U}, \mathrm{Y} 1, \mathrm{Y} 2)$. Percentage of cases showing complete filling was $71 \%$ in $\mathrm{V}$ and $\mathrm{U}$ types, $60.7-88.1 \%$ in $\mathrm{Y} 1$ and $23.6-57,6 \%$ in $\mathrm{Y} 2$ types.

\section{Conclusion}

The morphology of pit and fissure system provides a highly complex opportunity for sealant placement and prevention of caries. It cannot be presumed to be a simple trough to be filled in. Understanding of this complexity is continued by the researchers and some invasive and non invasive modifications have been studied and suggested by them, though they break the concept of ultra conservative approach in dentistry.

\section{References}

1. Hyatt TP (1923) Prophylactic Odontomy. Dental Cosmos 65: 324-341.

2. Gillings b, Buonocore M (1961) Thickness of enamel at the base of pits and fissures in human molars and bicuspids. J Dent Res 40: 119-133.

3. Robertson W (1841) A practical treatise on the human teeth. First American Ed Philadelphia: Lea and Blanchard.

4. Cho J, Kim DK (1989) Study on the shape and depth of the occlusal centra fissure in permanent molar teeth. Taehan Chikkwa Uisa Hyophoe Chi 27: 959964

5. http://compdent.uthscsa.edu/dig/

6. Juhl M (1983) Three-dimensional replicas of pit and fissure morphology in human teeth. Scand J Dent Res 91: 90-95.

7. Ripa LW (1973) Occlusal sealing: rationale of the technique and historical review. Journal of American Society of Preventive Dentistry 3: 32-39.

8. Galil KA, Gwinnett AJ (1975) Human tooth-fissure contents and their progressive mineralization. Arch Oral Biol 20: 559-562.

9. Powell KR, Craig GG (1978) An in vitro investigation of the penetrating efficacy of BIS-GMA resin pit and fissure coatings. J Dent Res 57: 691-695.

10. Sutalo J, PupiAV, Velenje T, Ciglar I, Skaljac G, et al. (1989) Scanning electron microscopic study of penetrability of sealants in relation to fissure morphology of permanent premolars in humans. Oralprophylaxe 11: 83-88. 